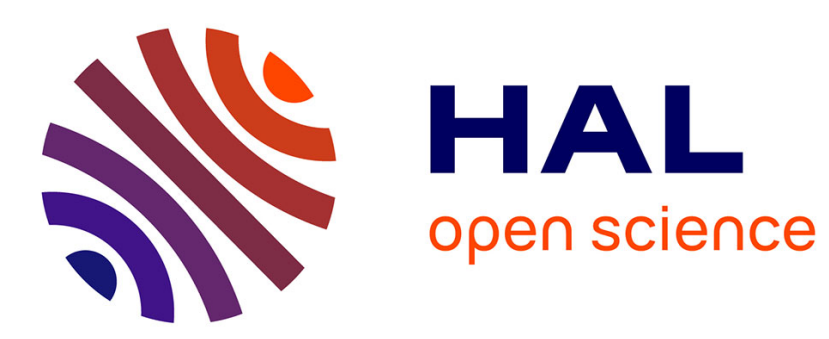

\title{
Reciprocity in Rapid Ethnography
}

Pieter Duysburgh, Karin Slegers

\section{To cite this version:}

Pieter Duysburgh, Karin Slegers. Reciprocity in Rapid Ethnography. 15th Human-Computer Interaction (INTERACT), Sep 2015, Bamberg, Germany. pp.292-299, 10.1007/978-3-319-22668-2_23 . hal-01599854

\section{HAL Id: hal-01599854 \\ https://hal.inria.fr/hal-01599854}

Submitted on 2 Oct 2017

HAL is a multi-disciplinary open access archive for the deposit and dissemination of scientific research documents, whether they are published or not. The documents may come from teaching and research institutions in France or abroad, or from public or private research centers.
L'archive ouverte pluridisciplinaire HAL, est destinée au dépôt et à la diffusion de documents scientifiques de niveau recherche, publiés ou non, émanant des établissements d'enseignement et de recherche français ou étrangers, des laboratoires publics ou privés. 


\title{
Reciprocity in Rapid Ethnography: Giving Back by Making the Small Things Count
}

\author{
Pieter Duysburgh ${ }^{1}$, Karin Slegers ${ }^{2}$ \\ ${ }^{1}$ iMinds - Digital Society, SMIT - VUB, Pleinlaan 9, 1050 Brussels, Belgium, \\ ${ }^{2}$ CUO, KU Leuven / iM inds, Parkstraat 45, bus 3605, 3000 Leuven, Belgium \\ pieter.duysburgh@vub.ac.be, karin.slegersesoc.kuleuven.be
}

\begin{abstract}
This paper responds to the discussion of a possible lack of reciprocity in applying ethnography in HCI research, sometimes referred to as 'rapid ethnography'. It contributes to the discussion by describing examples of how reciprocity can be achieved when applying rapid forms of ethnography. The paper suggests five approaches for HCI researchers to aim for reciprocity while doing research: (1) making participation fun for informants, (2) giving informants a voice, (3) allowing informants to exhibit their skills or strengths, (4) offering practical help and (5) providing self-knowledge. Each of these approaches comes with some risks, which are also explained in the paper. Reciprocity should be taken into consideration from the initial start of the research projects. Keywords. Ethnography; rapid ethnography; reciprocity.
\end{abstract}

\section{Introduction}

Ethnographic methods have become a common approach in HCI research since the computer became a mainstream device in the workplace and in everyday life [1]. In HCI research, the focus shifted increasingly towards the context of users or informants (i.e. the second wave). This context gradually changed: increasingly, homes or other places besides the workplace became of interest (i.e. the third wave). Ethnography became a prime research method in HCI research, since its holistic focus on groups or cultures (including their terrain or habitat) seemed a useful approach for HCI researchers to map the context of use of the technology they were working on. Many HCI research projects use at least some techniques finding their origin in ethnography (e.g. observations, interviews). However, there are fundamental differences between ethnography as it is commonly used in HCI, and traditional ethnography. Anderson [2] for instance, refers to a misunderstanding amongst HCI professionals, who tend to see ethnography as a method for data collection, while ethnographers rather see their methods as a form of analytic reportage. He suggests that it is not ethnography that designers need, but rather field experience to better understand the context of use. Dourish [3] continues to analyze this methodological view on ethnography in HCI. He emphasizes the lack of a perspectival view, which he finds critical to what ethnography is, as researchers in HCI try to be a passive instrument when 
using ethnographic methods to provide an objective representation of a setting. Of specific interest for this paper, is the idea of doing 'rapid ethnography', as coined by Millen [4].

Millen points out another problem with the use of ethnography in HCI, namely, the mismatch between ethnography's demand to spend (much) time in the field and the fast pace of research in HCI. Therefore, Millen suggests the use of the term 'rapid ethnography' to refer to the timesaving research methods commonly advocated in $\mathrm{HCI}$ ethnography. In his article, Millen describes the key ideas on which rapid ethnography is based: it departs from (1) narrowing down the focus of the field research, zooming in on important activities and using key informants; (2) using multiple interactive observation techniques to increase the likelihood of discovering exceptional and useful user behavior; and (3) using collaborative and computerized iterative data analyze methods.

While these ideas are widely accepted within $\mathrm{HCI}$ research, the use of these 'time deepening strategies' is not without its critics. A recent CHI paper by Brereton et al. [5] pointed out a particular challenge for researchers doing rapid ethnography. In this paper, the authors discussed the risk of a lack of reciprocity in a rapid ethnography approach: "Rapid forms of ethnography found in design research, run a particular risk of taking without giving back to communities and rushing to quick and possibly illconceived design approaches" [3, p. 1183]. They express concerns about a lack of attention for culturally appropriate methods for engagement and for ensuring that participation has a clear benefit for informants.

As HCI researchers, we identify with many of the struggles Brereton et al. describe, and agree that such issues should be discussed more in the CHI community. What we would especially like to discuss further is the authors' suggestion that HCI researchers should focus on engagement and reciprocity first, to ensure valid outcomes and avoid ill-conceived design solutions. While we agree on the importance of reciprocity in research, we also think that it is possible to focus on engagement and reciprocity while following a rapid ethnographic approach design. In our rapid ethnographic research, we - and we assume HCI researchers in general - often depart from the principles of participatory design in which mutual learning, equality between researchers and participants, and reciprocity are core values [6]. In this paper, we explore how reciprocity can be achieved in rapid ethnography and to what extent this requires HCI researchers to adjust their practices.

The contribution of this paper lies in the continuation of the discussion opened by Brereton et al. It argues how reciprocity can be a focal point in rapid ethnography, which is now so common in $\mathrm{HCl}$ research. We do this by describing how we, in our own experiences with rapid ethnography, explicitly try to give back to our informants. We realize that the insights and experiences that we describe in this paper are subjective and personal by nature. The story may lack systematic research for some of our assumptions and suggestions. But we see this paper as a contribution to the ongoing discussion that might inspire other researchers. 


\section{Reciprocity in rapid ethnography}

When informants, as experts of their own experience [7], give us insight into their lives, we as HCI researchers do feel the moral need to reciprocate this 'gift'. In line with the seminal writings of Mauss on 'the gift' [8], we understand the need for reciprocity as a requirement to achieve an alliance with other individuals or groups in order to build 'solidarity'. Reciprocity is not without self-interest, but it does hold a concern for others. When considering Graebers typology of reciprocity [9], it is clear that HCI researchers should avoid a situation of 'closed reciprocity', where the relationship resembles a form of market exchange. Here, both parties are individualistic and try to maximize their gains. This lack of solidarity is likely to result in a lack of mutual learning and, hence, ill-fitting design solutions. Instead, we should strive towards the ideal of 'open' reciprocity, or a relationship of mutual commitment, where no accounts are kept. This is also considered to be an essential element in particip atory design research, where a hybrid space is created between researchers and informants with little emphasis on authority and individualism [6]. This can result in more engaged informants and researchers, and ultimately, in better research. As such, there is both a moral and an epistemological component to reciprocity in $\mathrm{HCI}$ research: researchers are morally obligated to give back to their informants, while it may also improve their work.

Mutual commitment is often not only the goal of us, researchers. We notice that many of our informants regard their participation in our research similarly. For instance, although providing informants with a financial incentive is quite common in many research domains, we noticed that most our informants do not see financial gain as a main driver for their participation. Our informants often do not expect financial incentives; some even considered incentives as inappropriate. E.g. some informants participate in research, simply for the reason of making a contribution to science. By receiving a monetary incentive, their act of benevolence is turned into an act of monetary gain. Authors such as Sandel [10] have written extensively on how monetary gifts change the meaning of actions.

Therefore, while we certainly take incentives into account when recruiting informants, we try to look for other ways to ensure reciprocity in our research. Doing so does not necessarily require activities in addition to the original research (as Brereton et al [5] seem to suggest). Rather, we believe that it is possible to organize the research activities themselves in such a manner that they are not only meaningful for researchers but also for the informants. Below, we list a number of such ways and give examples of how reciprocity may be attained in rapid ethnography approaches.

\subsection{Making participation fun}

Fun and play are important parts of human activity [11]. In our opinion, aiming for pleasure during research can make a big difference in the experience of the informants and be a form of reciprocity in itself. When informants see their participation as a fun, enriching experience, they might see the activity itself as something that has been given to them. 
To illustrate this, we refer to the approach of a workshop organized recently for a project on information provision for train travellers [12]. These workshops were organized next to a series of observations and interviews. For the workshops, a board game was developed. On the game board, a train journey was visualized. The informants were divided into teams, and were asked to compete against each other to be the first to reach the final destination of the journey. During this journey they were confronted with several incidents and asked to express their need for information when facing such an incident in real life.

While the board game was very simple (the main rules were similar to those of The Game of the Goose and The Game of Life), this approach resulted a playful and relaxed atmosphere. An evaluation of the approach showed that informants felt like they were caught by (pleasant) surprise when the method was introduced to them. The evaluation survey illustrated that the majority of the informants enjoyed the workshop. They found it to be pleasantly different from previous research activities they were involved in. While all informants had received a monetary incentive as well, due to the fun nature of the workshops, it seemed that they regarded their involvement in the research as a valuable experience in itself.

Risks. Making informants' involvement more fun is usually more time consuming than traditional research setup. Also, there will most likely be at least one informant who does not enjoy the supposedly pleasant activity (which was also the case in the workshops with the board games). And worse, too much focus on 'fun' during methodological development might cause the researchers to loose focus and diverting their attention from their actual research questions.

\subsection{Giving informants a voice}

Ultimately, our informants' contributions should lead to the development of a new product or service. But as Brereton et al. [5] also point out, this cannot always be guaranteed. In fact, it is probably more likely that research valorization is less immediate and will rather be found in academic dissemination or in long-term insights for industrial partners involved. However, this does not necessarily frustrate informants. Often, it seems that informants are grateful to be given a voice, and find the opportunity to be heard valuable in itself. Often, informants have mentioned feelings of relief, thanking the interviewer for the attention and having enjoyed sharing their story.

As such, the responsibility of the researcher when interviewing cannot be overestimated. The interviewer has to ensure a gratifying conversation, and a pleasurable course of the interview, while also gathering the data required for the research. Depending on the type of interview, researchers have a topic list or a (semi-)structured questionnaire, but they should also have a flexible mindset and time schedule, be willing to deviate substantially from the original topic list and allow informants to tell the stories they would like to tell. While this is of course true for any interview, our experience is that researchers often find it difficult to substantially deviate from their topic list during interviews. While this is a standard approach in traditional ethnogra- 
phy, researchers doing rapid ethnography might at times have to allow interviews to take 30 minutes to a full hour longer than originally planned.

To illustrate this, we refer to research activities with informal caregivers in a project aimed at developing a platform for services for micromanagement in home care [13]. Researchers repeatedly visited informal caregivers at their homes to gain insights in their caring activities and their requirements for a platform for care coordination. Most of the caregivers were under considerable stress; some even experienced helplessness about the situation they were in. Participating in the project further heightened the pressure on their lives. However, several caregivers felt grateful for the attention they were given. The researchers did their best to make the conversations pleasurable experiences, and took the issues the informants raised at heart, often thinking along to find solutions for problems they brought up, even though they were often not directly related to the project. The interviews could theoretically be dealt with within less than an hour, but the researchers did not rush. Some interviews were very personal and emotional, touching upon deep frustrations or structural problems. Afterwards, several informants thanked the researchers involved extensively, having enjoyed the conversation.

Risks. The informants' expectations might differ considerably from the researchers' intentions. In one project [14], we interviewed persons with dementia and their family caregivers. As the informants were recruited via a hospital, some caregivers assumed that the interviewers would be able to give them medical advice. They would bring up medication and therapy schemes and wanted to discuss alternatives with the interviewers. Researchers should be as clear as possible about their goals and manage informants' expectations.

\subsection{Allowing informants to exhibit their strengths or skills.}

In line with the previous section is the idea of providing informants with a 'stage'. In this respect, informants are asked to do something they are really good at and enjoy showing to others. As such, the researchers becomes sort of an audience for the informants, affirming that they are good at something and endorsing their skills (cf. the teacher - student model in contextual inquiry [15]). This dynamic can raise the confidence of the informants, making them more comfortable and feel good about themselves.

In fact, in ethnographic HCI research, researchers often explicitly see their informants as 'experts of their experience' [7], reassuring them that they have something to contribute to the research (often informants are doubtful whether they have anything to contribute). Providing ways and/or tools to be at the center of attention when doing something informants are good at, or tell about something they are knowledgeable of, does not only provide us with valuable insights, it also gives something back to the them: they tend to feel better about themselves.

In the project with dementia patients mentioned above, for instance, the researchers discussed what activities the patients really liked doing, what they were really good at. This activity was then used as the basis for researcher-informant interactivity. Two researchers went over to a patient and her son to cook with them for instance, as 
mother and son liked doing this together, because the mother could still do many cooking tasks on her own.

Risks. Providing a stage for informants to show researchers what they are really good at or enjoy in some cases may result in informants slowly drifting away from the focus of the research. In such situations, it can be challenging for researchers to subtly steer their informants back to the topic of the study at hand.

\section{$2.4 \quad$ Offering practical help}

Perhaps the most obvious form of reciprocity is offering practical help to the informant. This does not necessarily imply that researchers have to organize activities in addition to the research activities. Rather, researchers can strive to help informants while doing research.

For instance, in the home care micromanagement project mentioned above, researchers observed a person taking care of meal deliveries for care receivers with high dependency. For a full day, this person and a researcher drove from home to home to deliver meals. Here, the researchers started assisting this person, getting out the car themselves to hand over the meals. Similarly, in another project [16], we also were of some assistance to teachers by taking over some of their teaching duties when organizing workshops with students during their teaching hours.

This type of practical assistance is not always feasible, especially not in highly specialized work environments (e.g. during observations in surgical theaters it was impossible to be of practical help [17]). But very often, there is an opportunity for researchers to be of some assistance. Even when such assistance is very limited, it does allow researchers to communicate their intention to strive for reciprocity and equality in the research process.

Risks. As always with participatory observation, the researchers should make sure that by helping they do not alter the situation in such a manner that the data obtained no longer hold any relation with the phenomena they wish to observe. Also, es pecially with frail target groups such as care receivers, offering help might have legal implications in case things do not go as planned.

\subsection{Providing self knowledge / mirroring}

While participating in research activities, or being presented with the outcomes of a research project one participated in, informants may be presented with considerable insights into their own lives, which can be deeply gratifying. For instance, cultural probes can stimulate reflection and encourage informants to closely examine certain facets of their lives, as to be more able to understand and verbalize their experiences more precisely [18]. In one project, we asked people who had recently retired to reflect on their experiences regarding this phase in their lives. We used an extensive package of cultural probes as a sensitization for later interviews and prototyping sessions. Some informants had put so much effort in the cultural probes that they refused to leave them behind. They felt the probes had become important objects reflecting 
their personal experience. They wanted to keep the probes, and share what they had learned about themselves with their family.

Risks. Although gaining self-knowledge can be deeply gratifying, it may also confront informants with an unpleasant reality they were not yet aware of or tried to forget or ignore. Self-knowledge can be confrontational: when aiming for this type of reciprocity, researchers should carefully consider the consequences of increased selfknowledge.

\section{Discussion \& conclusion}

In this paper we discussed several ways in which we try to give back to our informants during rapid ethnography. By doing this, we aimed to show that HCI research is not always about taking without giving back, as was identified by Brereton et al. [5] as a risk. We do agree that the rapid approach to ethnography is very different from traditional ethnography. However, we also firmly belief that rapid ethnography does not exclude engagement and reciprocity. We hope that our reflections inspire HCI researchers also striving for open reciprocity, mutual commitment or equal relationships in their research. While taking up some of these strategies might require an additional effort from the researchers involved, they do not require them to organize activities in addition to those activities planned for data gathering. They can be used in combination with the time deepening strategies as formulated by Millen, without having to resort to a traditional ethnographic study.

We fully agree with Brereton et al. that reciprocity should be considered first and foremost when working with informants, both for moral and epistemological reasons. Therefore, we plead for other researchers in the HCI community to take reciprocity into consideration from the start of any research project. We also think that reciprocity can be achieved in numerous small ways without having to set up additional activities, of which we gave a number of examples in this paper.

We realize that our ways of giving back to our informants may not always be very concrete or tangible. However, we find it important that HCI researchers share their attempts at reciprocity, as we did in this paper. By sharing such experiences, and by continuing the discussion about ethnography in HCI, we believe that it is possible to reduce the risks that are related to rapid ethnography, and to further improve the quality of ethnographic research in HCI.

\section{$4 \quad$ References}

1. Crabtree, D.A., Rouncefield, D.M., Tolmie, D.P.: Ethnography and Systems Design. Doing Design Ethnography. pp. 7-19. Springer London (2012).

2. Anderson, R.J.: Representations and Requirements: The Value of Ethnography in System Design. Hum-Comput Interact. 9, 151-182 (1994).

3. Dourish, P.: Implications for Design. Proceedings of the SIGCHI Conference on Human Factors in Computing Systems. pp. 541-550. ACM, New York, NY, USA (2006). 
4. Millen, D.R.: Rapid Ethnography: Time Deepening Strategies for HCI Field Research. Proceedings of the 3rd Conference on Designing Interactive Systems: Processes, Practices, Methods, and Techniques. pp. 280-286. ACM, New York, NY, USA (2000).

5. Brereton, M., Roe, P., Schroeter, R., Lee Hong, A.: Beyond Ethnography: Engagement and Reciprocity As Foundations for Design Research out Here. Proceedings of the $32 \mathrm{Nd}$ Annual ACM Conference on Human Factors in Computing Systems. pp. 1183-1186. ACM, New York, NY, USA (2014).

6. Muller, M.J., Druin, A.: Participatory design: the third space in HCI. In: Jacko, J.A. and Sears, A. (eds.) The human-computer interaction handbook. pp. 1051-1068. L. Erlbaum Associates Inc., Hillsdale, NJ, USA (2003).

7. Visser, F.S., Stappers, P.J., van der Lugt, R., Sanders, E.B.-N.: Contextmapping: experiences from practice. CoDesign. 1, 119-149 (2005).

8. Mauss, M.: The Gift: The Form and Reason for Exchange in Archaic Societies. W. W. Norton \& Company, New York (2000).

9. Graeber, D.: Toward an anthropological theory of value: the false coin of our own dreams. Palgrave Macmillan, Basingstoke, UK (2001).

10. Sandel, M.: What Money Can't Buy. Penguin, London (2013).

11. Huizinga, J.: Homo Ludens: A Study of the Play-Element in Culture. Beacon Press, Boston (1971).

12. Slegers, K., Ruelens, S., Vissers, J., Duysburgh, P.: Using Game Principles in UX Research: A Board Game for Eliciting Future User Needs. Proceedings of the 33rd Annual ACM Conference on Human Factors in Computing Systems. pp. 1225-1228. ACM, New York, NY, USA (2015).

13. iMinds: O'CareCloudS. Organizing home care using a cloud-based platform, http://www.iminds.be/en/projects/2014/04/07/ocareclouds, (2012).

14. Slegers, K., Wilkinson, A., Hendriks, N.: Active Collaboration in Healthcare Design: Participatory Design to Develop a Dementia Care App. CHI '13 Extended Abstracts on Human Factors in Computing Systems. pp. 475-480. ACM, New York, NY, USA (2013).

15. Beyer, H., Holtzblatt, K.: Contextual Design: Defining Customer-Centered Systems. Elsevier (1997).

16. Slegers, K., Duysburgh, P., Jacobs, A.: Research methods for involving hearing impaired children in IT innovation. Proceedings of the 6th Nordic Conference on Human-Computer Interaction: Extending Boundaries. pp. 781-784. ACM, New York, NY, USA (2010).

17. Duysburgh, P., Elprama, S.A., Jacobs, A.: Exploring the Social-technological Gap in Telesurgery: Collaboration Within Distributed or Teams. Proceedings of the 17th ACM Conference on Computer Supported Cooperative Work \&\#38; Social Computing. pp. 1537-1548. ACM, New York, NY, USA (2014).

18. Gaver, B., Dunne, T., Pacenti, E.: Design: Cultural Probes. interactions. 6, 21-29 (1999). 